\title{
Software-recorded and self-reported duration of computer use in relation to the onset of severe arm-wrist-hand pain and neck-shoulder pain
}

\author{
Stefan IJmker, ${ }^{1,2,3}$ Maaike A Huysmans, ${ }^{1,2}$ Allard J van der Beek, ${ }^{1,2}$ Dirk L Knol, ${ }^{4}$ \\ Willem van Mechelen, ${ }^{1,2}$ Paulien M Bongers, ${ }^{1,2,3}$ Birgitte M Blatter ${ }^{1,3}$
}

1Body@Work Research Centre on Physical Activity, Work and Health, TNO-VUNUmc, Amsterdam, The Netherlands ${ }^{2}$ Department of Public and Occupational Health, EMGO Institute for Health and Care Research, VU University Medical Center, Amsterdam, The Netherlands

${ }^{3}$ TNO Quality of Life, Hoofddorp, The Netherlands ${ }^{4}$ Department of Clinical Epidemiology and Biostatistics, EMGO Institute for Health and Care Research, VU University Medical Center (VUmc). Amsterdam, The Netherlands

\section{Correspondence to}

Dr Birgitte Blatter, TNO Quality of Life, Polarisavenue 151, 2132 JJ Hoofddorp, The Netherlands; birgitte.blatter@tno.n

Accepted 30 September 2010 Published Online First

2 November 2010

\section{ABSTRACT}

Objectives In both science and media, the adverse effects of a long duration of computer use at work on musculoskeletal health have long been debated. Until recently, the duration of computer use was mainly measured by self-reports, and studies using more objective measures, such as software-recorded computer duration, were lacking. The objective of this study was to examine the association between duration of computer use at work, measured with software and self-reports, and the onset of severe arm-wrist-hand and neck-shoulder symptoms.

Methods A 2-year follow-up study was conducted between 2004 and 2006 among 1951 office workers in The Netherlands. Self-reported computer duration and other risk factors were collected at baseline and at 1 -year follow-up. Computer use at work was recorded continuously with computer software for 1009 participants. Outcome questionnaires were obtained at baseline and every 3 months during follow-up. Cases were identified based on the transition within 3 months of no or minor symptoms to severe symptoms.

Results Self-reported duration of computer use was positively associated with the onset of both arm-wrist-hand (RR 1.9, 95\% Cl 1.1 to 3.1 for more than $4 \mathrm{~h}$ /day of total computer use at work) and neck-shoulder symptoms (RR $1.5,95 \% \mathrm{Cl} 1.1$ to 2.0 for more than $4 \mathrm{~h} /$ day of mouse use at work). The recorded duration of computer use did not show any statistically significant association with the outcomes.

Conclusions In the present study, no association was found between the software-recorded duration of computer use at work and the onset of severe arm-wrist-hand and neck-shoulder symptoms using an exposure window of 3 months. In contrast, a positive association was found between the self-reported duration of computer use at work and the onset of severe arm-wrist-hand and neck-shoulder symptoms. The different findings for recorded and self-reported computer duration could not be explained satisfactorily.

\section{INTRODUCTION}

The question of whether a long duration of computer use at work challenges musculoskeletal health has long been debated. ${ }^{1-4}$ In prospective cohort studies, a dose-response relationship was found between the self-reported duration of mouse use at work and hand-arm symptoms. ${ }^{5}$ However, the validity of self-reports in order to assess computer duration can be questioned. ${ }^{6}$ Previous studies have shown that computer

\section{What this paper adds}

- Only a few studies allow inference on the effect of software-recorded duration of computer use on the onset of arm-wrist-hand and neckshoulder symptoms.

- This study found that software-recorded duration of computer and mouse use at work was not significantly associated with severe armwrist-hand or neck-shoulder symptoms, whereas self-reported computer and mouse use was.

- Future studies are advised to focus on a milder case definition and to explore more detailed measures of exposure, such as peak exposure or the absence of variability in exposure.

workers overestimate their duration of computer use at work, ${ }^{6-8}$ and that this overestimation is mainly non-differential in nature. ${ }^{6}$ This would lead to an underestimation of the true exposureresponse relationship. ${ }^{9}$ The use of computer software to measure the duration of computer use, which has been shown to have a good agreement with observations, ${ }^{10}{ }^{11}$ may be useful in establishing more validly the relationship between computer duration and symptoms.

Two recent prospective cohort studies used software recordings to assess the duration of computer use at work and confirmed the positive association between the duration of computer use at work and the onset of arm-wrist-hand and neck-shoulder symptoms. ${ }^{12} 13$ Surprisingly, the strength of associations in these studies with software-recorded computer duration was generally weaker than previously reported for self-reported computer duration. ${ }^{5}$ In addition, a long duration of computer mouse use at work was only associated with acute symptoms, and not with prolonged symptoms. ${ }^{12}$ However, comparison of the results of studies using self-reports and those using software-recorded computer duration is complicated by the fact that none of these studies used the same case definition. Case definitions varied from acute to prolonged pain, from mild to severe pain levels, with or without pain medication or medical examination and recall periods varied from 1 day to 1 year. ${ }^{512} 13$

Although the debate on the potential effect of the duration of computer use at work on the onset of arm-wrist-hand and neck-shoulder symptoms 
has been ongoing for decades, this is only the third study to allow inference on the effect of software-recorded duration of computer use on the onset of arm-wrist-hand and neck-shoulder symptoms. In addition, to date, no study has investigated the associations between both self-reported and software-recorded duration of computer use at work and the onset of symptoms, in one population using the same case definition. Therefore, the current study examines the association between the duration of computer use at work and the onset of severe arm-wrist-hand and neck-shoulder symptoms, by using both software-recorded and self-reported measures of computer duration.

\section{METHODS}

\section{Design and study population}

A prospective cohort study with a 2-year follow-up was performed among a diverse group of office workers in The Netherlands; The Prospective Research On Musculoskeletal disorders among Office workers (PROMO). The cohort was established in 2004, and data were collected in the period 2004-2006. Outcome was assessed every 3 months by means of a questionnaire. Risk factors were assessed with a questionnaire at baseline and after 1 year of follow-up. Data on exposure and outcome were collected using web-based self-reports. Participants received an email containing a link to the questionnaire. By request, participants could fill out a hard copy of the questionnaire. In case of non-response, participants received a maximum of two reminders by email 10 and 20 days after sending the initial request respectively. For a subgroup of 1009 workers, continuous recording of the duration of computer use at work by a software program was available. The Medical Ethics Committee of the VU University Medical Centre (VUmc) approved the study design and subjects signed informed consent forms before study participation. Additional information on the design of the PROMO study can be found elsewhere. ${ }^{14}$

Participants were recruited from five organisations, which included public and private organisations. The main work tasks of the participants were computer-related tasks, attending meetings, making phone calls and giving presentations.

Out of 9161 approached employees, 2461 (27\%) signed informed consent, and 1951 participants (79\%) filled out the baseline questionnaire. Of these 1951, 1013 (52\%) filled out all eight consecutive questionnaires (see table 1). The questionnaire response rate, calculated as baseline response plus at least two consecutive outcome responses, dropped to $74 \%$ (1448 participants) after 1 year of follow-up and to $68 \%$ (1324 participants) after 2 years of follow-up. For 1009 participants $(52 \%)$, software recordings of the duration of computer use at work were available for at least one 3-month period (see table 1). For the remaining 942 participants (48\%) no or no valid recordings were available (not valid means that the number of recorded days was less than $70 \%$ of the expected working days, due to technical problems for example).

In order to allow comparison of participants and non-participants, in one of the five companies information was gathered of the non-participants. In this company, software to record computer use (Wellnomics WorkPace version 3.0, Wellnomics Ltd/ErgoDirect) was installed at all workstations, and the company provided the mean recorded duration of computer use of the non-participants. Moreover, the company provided descriptive data on age, gender and job contract. For the participants in this study, only self-reported data on age, gender and job contract were used.

\section{Assessment of determinants, effect modifiers and confounders}

The duration of computer use at work was measured by software recordings (Wellnomics WorkPace version 3.0, Wellnomics $\mathrm{Ltd} /$ ErgoDirect) and by questionnaires. The software program recorded all activities performed with the keyboard or the mouse. The program estimated the duration of computer use on the basis of the duration of the time interval between two consecutive active events (ie, keying, clicking or mouse movements). If a participant hit a key, moved or clicked the mouse within $30 \mathrm{~s}$ of previously hitting a key or moving or clicking the mouse, then the 'interevents period' (in seconds) was stored as a usage period of total computer use. If the threshold time of $30 \mathrm{~s}$ was exceeded, then the elapsed time period was stored as a break from total computer use. This threshold value for total computer use reflects the use of the keyboard or mouse, reading from the screen and performing combinations of these activities. This was based on previous studies, in which it was found that the average duration of total computer use based on WorkPace estimates was within $10 \%$ of the average duration of total computer use based on systematic observation. ${ }^{10} 11$ The threshold time for mouse use, which reflects clicking or moving the mouse (and not reading from the screen) was $5 \mathrm{~s}$. The threshold time for keyboard use, which reflects hitting the keys

Table 1 Number of participants (as a percentage of total N) for whom a specific number of 3-month periods of data were available

\begin{tabular}{|c|c|c|c|c|}
\hline $\begin{array}{l}\text { No of 3-month periods for } \\
\text { which data were available }\end{array}$ & $\begin{array}{l}\text { Questionnaire } \\
\text { data on outcome } \\
(\mathrm{N}=1951)\end{array}$ & $\begin{array}{l}\text { Original } \\
\text { recorded } \\
\text { computer data } \\
(\mathrm{N}=1951)\end{array}$ & $\begin{array}{l}\text { Total recorded } \\
\text { computer data } \\
\text { (original and } \\
\text { imputed data) } \\
(\mathrm{N}=1951)\end{array}$ & $\begin{array}{l}\text { Imputed recorded } \\
\text { computer data (as } \\
\text { a percentage of } \\
\text { the total no of } \\
\text { participants with } \\
\text { recorded computer } \\
\text { data, ie, } N=1009 \text { ) }\end{array}$ \\
\hline 9 (ie, for all nine periods data available) & $1013(52 \%)$ & $0(0 \%)$ & $0(0 \%)$ & $0(0 \%)$ \\
\hline 8 (ie, for one period data missing) & $266(14 \%)$ & $2(0 \%)$ & $2(0 \%)$ & $0(0 \%)$ \\
\hline 7 & $141(7 \%)$ & $31(2 \%)$ & $158(8 \%)$ & $0(0 \%)$ \\
\hline 6 & $101(5 \%)$ & $44(2 \%)$ & $121(6 \%)$ & $0(0 \%)$ \\
\hline 5 & $66(3 \%)$ & $55(3 \%)$ & $187(10 \%)$ & $10(1 \%)$ \\
\hline 4 & $132(7 \%)$ & $218(11 \%)$ & $144(7 \%)$ & $21(2 \%)$ \\
\hline 3 & $80(4 \%)$ & $156(8 \%)$ & $106(5 \%)$ & $306(30 \%)$ \\
\hline 2 & $78(4 \%)$ & $308(16 \%)$ & $166(9 \%)$ & $33(3 \%)$ \\
\hline 1 & $74(4 \%)$ & $195(10 \%)$ & $125(6 \%)$ & $93(9 \%)$ \\
\hline 0 (ie, no data available) & & $942(48 \%)$ & $942(48 \%)$ & $546(54 \%)$ \\
\hline
\end{tabular}


on the keyboard, was $2.5 \mathrm{~s}$. These different thresholds for total computer duration, mouse duration and keyboard duration mean that total computer time is not merely the sum of mouse duration and keyboard duration.

From the software recordings, we calculated the average weekly duration of computer use at work for each 3-month period during follow-up by dividing the cumulative time of usage in a 3-month period by the number of weeks in that period. The same was done for keyboard use and mouse use separately.

Data were set to missing if the number of recorded days was less than $70 \%$ of the number of expected working days in that specific 3-month period (ie, the number of working days according to the job contract adjusted for self-reported sick leave, pregnancy leave, vacation or leave from work for other reasons). For the missing data we imputed data (last observation carried forward), based on the finding that in the present study the between subject variation in duration of computer use was five times higher than the within subject variation for successive 3-month periods. For 546 (46\%) of the 1009 participants with recorded computer duration, data for at least one 3-month period were imputed, and for $306(30 \%)$ of the participants data for three 3-month periods were imputed (see table 1). The proportion of total computer duration data that was imputed was $29 \%$. Participants who worked at least 2 days per week at another location of their organisation where no recordings could be made, and participants who shared a computer account with a colleague were excluded from the analyses.

Both the baseline questionnaire and the questionnaire that was sent after 1 year's follow-up contained questions on the duration of computer use at work. The exact wording was: 'How many hours per day do you use your computer during your work at the office (including reading from the screen)?' The question had seven response categories: never, 0-1, 1-2, 2-4, $4-6,6-8,>8 \mathrm{~h}$ per day (only one answer was possible). A similar question was used for the duration of mouse use.

A priori, we selected potential effect modifiers and confounders (see appendix 1) based on previously reported risk factors ${ }^{14}$ and on a pathophysiological hypothesis, in which continuous muscle activation plays an important role in the onset of arm-wrist-hand and neck-shoulder symptoms. ${ }^{15-18}$ These effect modifiers and confounders were measured with self-reports at baseline and at 1 year's follow-up. For more information on the exact questions used, see IJmker et al. ${ }^{14}$

\section{Outcome measurement}

Every 3 months, data concerning symptoms were gathered by means of a validated, modified version of the Nordic Questionnaire. ${ }^{19} 20$ Symptoms in the arm-wrist-hand region and neck-shoulder region were assessed separately. This choice was based on previous work that suggested that the effect of computer use on these two body regions is different. ${ }^{5} 21$ Participants were asked whether they experienced pain or discomfort in their arm-wrist-hand or in their neck-shoulder in the past 3 months. The response categories were 'no, never,' 'yes, sometimes,' 'yes, regularly' and 'yes, prolonged.' If participants experienced symptoms regularly or prolonged, they were asked to rate the pain intensity for their worst symptoms in the past 3 months on a Von Korff scale. ${ }^{22}$ The Von Korff scale is a validated 11-point numerical rating scale ranging from 0 'no pain' to 10 'pain as bad as could be. ${ }^{22}$ Next, participants were asked whether they used pain medication as a consequence of their symptoms.

Following Marcus et $a l,{ }^{23}$ cases were identified based on the transition no, irregular or minor symptoms to regular or prolonged symptoms together with a pain intensity exceeding 6 on a Von Korff scale for worst symptoms or medication use to control symptoms. ${ }^{20}$

The transition was defined based on the outcome measurement over a 3-month recall period, as compared with the outcome measurement of the preceding 3-month period (see figure 1). In a previous study among computer users, this selfreported case definition was associated with the same risk factors as a case definition based on physical examination. ${ }^{23}$ Each time the symptom status of a participant changed during follow-up, this was treated as a new case in the analysis.

\section{Statistical analysis}

Generalised Estimating Equations (GEE, STATA 7.0) were used to estimate rate ratios (RRs) for becoming a case. ${ }^{24}$ Separate analyses were performed for the neck-shoulder and arm-wristhand regions, and for self-reported and recorded duration of computer use. Numerical variables were divided into quartiles. The variables for the recorded duration of computer use at work were divided into tertiles, because of the lower number of available observations. If the RRs in univariate analyses were similar for a given outcome, adjacent categories were collapsed. In this way, we strove to use the lowest number of categories in order to

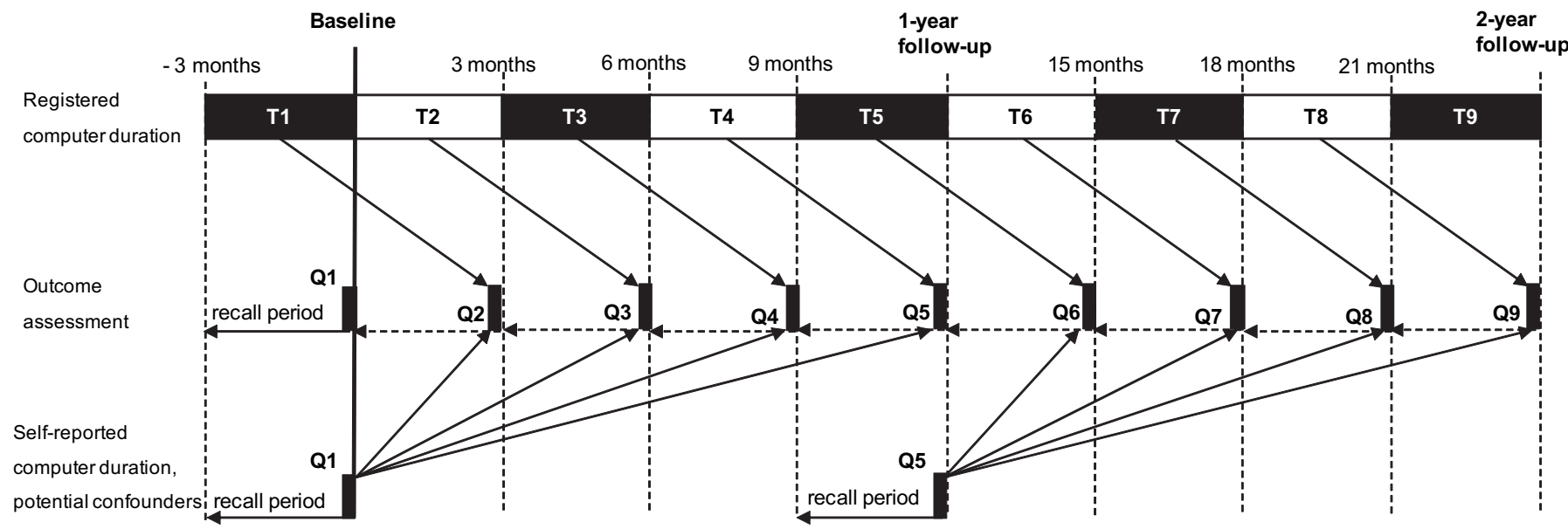

and effect modifiers

Figure 1 Schematic overview of the data collection and the statistical analyses. (T1 to T9 are the nine time periods; 01 to 09 are the nine questionnaires). 
increase precision, without losing relevant dose-response information. Variables measured at baseline and at 1-year follow-up were treated as constants for each 3-month period during the following year of follow-up. Covariates measured at baseline only were treated as constants for all 3-month periods during follow-up (appendix 1). In order to ensure a longitudinal analysis, exposure in a 3-month period predicted outcome in the next 3 months for all exposure variables (see figure 1).

Univariate analyses were performed separately for each potential effect modifier/confounder. If the $p$ value of the Wald test was lower than or equal to 0.20 , the variable was retained for further analysis. ${ }^{23}$ The remaining variables were then screened for multicollinearity. If the correlation between two variables exceeded 0.50 (arbitrary cut-off), the variable with the strongest association with the outcome was retained. Subsequently, we explored effect modification with the remaining variables. Effect modification was assumed to be present if the $\mathrm{p}$ Value of the Wald test of the interaction term was lower than or equal to 0.05 in a model, which included the main effects. Finally, a full model with all the remaining potential confounders was tested. If the $\mathrm{p}$ Value of the Wald test exceeded 0.10 , the potential confounder was excluded from the final model in order to increase precision. ${ }^{25}$

\section{RESULTS}

\section{Baseline characteristics}

There were two potential sources of selection bias in the present study. First of all, people who decided not to participate in the study could be different from those who participated in the present study. A second source of selection bias could have been a difference between the 942 participants without softwarerecorded computer duration (48\%) and the 1009 participants with software-recorded computer duration (52\%). Also, participants with missing data during follow-up could be different from those without missing data.

Therefore, baseline characteristics for participants without missing data during follow-up (ie, all nine questionnaires were completed), participants with missing data during follow-up (ie, at least one complete outcome assessment was missing during follow-up) and non-participants from one company were compared (see table 2). Non-participants used the computer less than participants $(11.0 \mathrm{~h}$ per week vs $11.8-12.4 \mathrm{~h} / \mathrm{w})$. Participants with missing data during follow-up had a shorter mean job tenure than participants without missing data during follow-up ( 9.9 years vs 12.5 years), reported more often $\geq 6$ h per day of computer use at work (49\% vs $43 \%$ ), were younger ( 39 years vs 41 years), were more often female (53\% vs 43\%) and reported more often neck-shoulder symptoms at baseline $(17 \%$ vs $13 \%)$. For other evaluated variables, no large differences were present between participants and non-participants, or between participants with and without missing data during follow-up. Baseline characteristics of the 942 participants without recorded computer data were not different from those of the 1009 participants with software-recorded computer data either (data not in table).

\section{Incidence}

The 3-month incidence for neck-shoulder cases varied between $3.9 \%$ and $8.8 \%$, and for arm-wrist-hand cases between $2.8 \%$ and $4.6 \%$ during the respective follow-up periods (table 3 ). In $10 \%$ of all cases, new symptoms appeared in both the arm-wrist-hand and the neck-shoulder region at the same time.

During the 2 years of follow-up, one out of every five participants $(20 \%)$ became a single neck-shoulder case, and one out of every seven participants (14\%) became a single arm-wrist-hand case (table 4). The incidence of becoming a case more than once during the 2 years of follow-up ('recurrent cases') was $6.1 \%$ of all participants for the neck-shoulder region and $4.1 \%$ for the arm-wrist-hand region (table 4). The largest part of the cohort never became a case: $82 \%$ of all participants never had severe arm-wrist-hand symptoms, and 73\% never had severe neckshoulder symptoms during the 2 years of follow-up (table 4 ).

\section{Associations}

Subjects who reported using the computer at work for 4-6 h per day were almost twice as likely as subjects reporting less than $4 \mathrm{~h}$ per day to become an arm-wrist-hand case during followup (RR 1.9, 95\% CI 1.1 to 3.1; see table 5). The risk of becoming an arm-wrist-hand case did not increase further for subjects reporting at least $6 \mathrm{~h}$ of computer use per day (RR 2.0, 95\% CI 1.2 to 3.2). For the duration of self-reported mouse use, a moderate association was found with arm-wrist-hand

Table 2 Baseline characteristics of participants and non-participants

\begin{tabular}{|c|c|c|c|c|c|c|}
\hline & \multicolumn{2}{|c|}{$\begin{array}{l}\text { Participants with no } \\
\text { missing data during } \\
\text { follow-up }\end{array}$} & \multicolumn{2}{|c|}{$\begin{array}{l}\text { Participants with } \\
\text { missing data during } \\
\text { follow-up* }\end{array}$} & \multicolumn{2}{|c|}{ Non-participants } \\
\hline & $\mathbf{n}$ & $\% /$ mean (SD) & $\mathbf{n}$ & $\% /$ mean (SD) & $\mathbf{n}$ & $\% /$ mean (SD) \\
\hline Mean company tenure (years) & 1010 & $12.5(10.6)$ & 937 & $9.9(9.8)$ & 2926 & $10.9(9.9)$ \\
\hline Mean job contract (h/week) & 1010 & $34.5(7.3)$ & 937 & $33.9(7.3)$ & 2926 & $34.3(6.7)$ \\
\hline Mean recorded duration of computer use at work (h/week) & 272 & $12.4(4.0)$ & 189 & $11.8(4.4)$ & 1017 & $11.0(5.6)$ \\
\hline \multicolumn{7}{|l|}{ Self-reported duration of computer use at work (h/day) } \\
\hline 0 to $<4$ & 147 & 15 & 129 & 14 & $-\dagger$ & $-\dagger$ \\
\hline 4 to $<6$ & 428 & 42 & 351 & 37 & & \\
\hline$\geq 6$ & 437 & 43 & 458 & 49 & & \\
\hline \multicolumn{7}{|l|}{ Individual characteristics } \\
\hline Age (years) & 1006 & $41.4(9.6)$ & 915 & $38.9(9.8)$ & 2926 & $39.6(9.3)$ \\
\hline Female gender & 1013 & 43.4 & 938 & 52.7 & 2926 & 44.5 \\
\hline Prevalent neck-shoulder symptoms in past 3 months & 1013 & 12.8 & 938 & 17.2 & $-\dagger$ & $-\dagger$ \\
\hline Prevalent arm-wrist-hand symptoms in past months & 1013 & 9.7 & 938 & 11.4 & $-\dagger$ & $-\dagger$ \\
\hline Disability owing to neck-shoulder symptoms in past year & 1013 & 26.1 & 938 & 26.3 & $-\dagger$ & $-\dagger$ \\
\hline Disability owing to arm-wrist-hand symptoms in past year & 1013 & 18.8 & 938 & 21.2 & $-\dagger$ & $-\dagger$ \\
\hline
\end{tabular}

*At least one complete outcome assessment missing during follow-up.

†No data available.

$\mathrm{n}$, number of subjects. 
Table 3 Number of cases* $^{*}$ with severe arm-wrist-hand symptoms or severe neck-shoulder symptoms during follow-up

\begin{tabular}{|c|c|c|c|c|c|c|c|c|}
\hline \multirow[b]{2}{*}{ Body region } & \multicolumn{8}{|c|}{ Follow-up instance } \\
\hline & $\begin{array}{l}\text { 3-month } \\
(n=1781 \dagger)\end{array}$ & $\begin{array}{l}\text { 6-month } \\
(n=1779 \neq)\end{array}$ & $\begin{array}{l}\text { 9-month } \\
(n=1761 \ddagger)\end{array}$ & $\begin{array}{l}\text { 12-month } \\
(n=1528 \neq)\end{array}$ & $\begin{array}{l}\text { 15-month } \\
(n=1436 \neq)\end{array}$ & $\begin{array}{l}\text { 18-month } \\
(n=1426 \neq)\end{array}$ & $\begin{array}{l}\text { 21-month } \\
(n=1411 \neq)\end{array}$ & $\begin{array}{l}\text { 24-month } \\
(n=1352 \ddagger)\end{array}$ \\
\hline Arm-wrist-hand & $54(3.0)$ & $68(3.8)$ & $78(4.4)$ & $67(4.4)$ & $57(4.0)$ & $65(4.6)$ & $58(4.1)$ & $38(2.8)$ \\
\hline Neck-shoulder & $90(5.1)$ & $124(7.0)$ & $82(4.7)$ & $135(8.8)$ & $78(5.4)$ & $82(5.8)$ & $55(3.9)$ & $60(4.4)$ \\
\hline
\end{tabular}

*Case definition: transition within 3 months of no, irregular or 'minor' symptoms to regular or prolonged symptoms together with a pain intensity exceeding 6 on a Von Korff scale or medication use to control pain (absolute number of cases). The number of cases as a percentage of the total number of participants at a particular follow-up instance is shown in parentheses.

†Subjects who responded at baseline and at 3-month follow-up.

$\ddagger$ Subjects who responded at baseline, at the particular follow-up instance and at the preceding follow-up instance.

symptoms (RR $1.4,95 \%$ CI 0.9 to 2.1 for at least $4 \mathrm{~h}$ per day vs zero to $2 \mathrm{~h}$ per day). For the neck-shoulder region, we found no association between the self-reported duration of total computer use at work and case status during follow-up. Subjects who reported at least $4 \mathrm{~h}$ per day of mouse use at work, however, had a moderately increased risk of developing neck-shoulder symptoms (RR $1.5,95 \%$ CI 1.1 to 2.0 ).

The recorded duration of total computer use, mouse use and keyboard use at work was not associated with the onset of arm-wrist-hand symptoms or with the onset of neckshoulder symptoms. On average, participants had a recorded computer duration of $12.5(\mathrm{SD}=4.5) \mathrm{h}$ per week, a mouse duration of $6.6(\mathrm{SD}=3.1) \mathrm{h}$ per week and a recorded keyboard duration of $3.1(\mathrm{SD}=1.5) \mathrm{h}$ per week. This was the case both when calculated with imputed data and when calculated without imputed data.

Precision demands at work and duration of computer use during leisure time modified the association between the selfreported duration of computer use at work and the onset of severe arm-wrist-hand symptoms. For participants with low precision demands at work or longer hours of self-reported computer use during leisure time, the association between selfreported computer duration at work and severe arm-wristhand symptoms was stronger, while for participants with high precision demands and hardly any self-reported computer use in leisure time, this association was weaker (data not presented). For all other evaluated associations, no effect modifiers were identified.

\section{DISCUSSION}

Previous studies have shown that office workers overestimate their duration of computer use at work, as compared with the recorded duration of computer use at work. ${ }^{6-8}$ This leads to a high degree of non-differential misclassification of self-reported duration of computer use as compared with software-recorded computer duration. ${ }^{6}$ Based on these findings, the expectation was that recorded computer duration would show stronger associations with the onset of symptoms than self-reported duration of computer use. ${ }^{5}$ However, recorded data on the duration of computer use at work did not show any association with case status during follow-up, while self-reported duration

Table 4 Number of times that a participant became a (recurrent) case with arm-wrist-hand symptoms and neck-shoulder symptoms

\begin{tabular}{llllll}
\hline & \multicolumn{6}{l}{$\begin{array}{l}\text { No of times that a participant became a (recurrent) } \\
\text { case }\end{array}$} & \multicolumn{1}{l}{} \\
\cline { 2 - 6 } & $\mathbf{0}$ & $\mathbf{1}$ & $\mathbf{2}$ & $\mathbf{3}$ & $\mathbf{4}$ \\
\hline $\begin{array}{l}\text { Arm-wrist-hand } \\
(\mathrm{N}=1951)\end{array}$ & $1592(82 \%)$ & $279(14 \%)$ & $68(4 \%)$ & $10(1 \%)$ & $2(0 \%)$ \\
$\begin{array}{l}\text { Neck-shoulder } \\
(\mathrm{N}=1951)\end{array}$ & $1433(73 \%)$ & $398(20 \%)$ & $100(5 \%)$ & $20(1 \%)$ & \\
\hline
\end{tabular}

of computer use yielded positive associations with the onset of both severe arm-wrist-hand and neck-shoulder symptoms.

\section{Association between self-reported duration of computer use and severe symptoms}

The association between self-reported duration of computer use and the onset of severe arm-wrist-hand and neck-shoulder symptoms found in the present study is fully in line with the results from a review which summarised the evidence from nine longitudinal cohort studies. ${ }^{5}$ In addition, it was found in the present study that risk-estimates were in general larger for becoming an arm-wrist-hand case than for becoming a neck-shoulder case. This was in line with the review, too. ${ }^{5}$

Table 5 Univariate and multivariate associations between self-reported and recorded duration of computer use at work and arm-wrist-hand and neck-shoulder cases

\begin{tabular}{|c|c|c|c|c|}
\hline \multirow[b]{2}{*}{$\begin{array}{l}\text { Exposure } \\
\text { variable }\end{array}$} & \multicolumn{2}{|c|}{ Arm-wrist-hand } & \multicolumn{2}{|l|}{ Neck-shoulder } \\
\hline & $\begin{array}{l}\text { Univariate } \\
\text { RR (95\% CI) }\end{array}$ & $\begin{array}{l}\text { Multivariate* } \\
\text { RR (95\% CI) }\end{array}$ & $\begin{array}{l}\text { Univariate } \\
\text { RR (95\% Cl) }\end{array}$ & $\begin{array}{l}\text { Multivariate } \dagger \\
\text { RR (95\% CI) }\end{array}$ \\
\hline \multicolumn{5}{|c|}{ Self-reported duration of total computer use at work, $\mathrm{h} /$ day } \\
\hline 0 to $<4$ & 1 & 1 & 1 & 1 \\
\hline 4 to $<6$ & $1.4(0.9$ to 2.2$)$ & $1.9(1.1$ to 3.1$)$ & $1.3(0.9$ to 1.7$)$ & $1.1(0.8$ to 1.5$)$ \\
\hline$\geq 6$ & $2.0(1.3$ to 3.0$)$ & $2.0(1.2$ to 3.2$)$ & 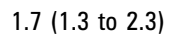 & $1.2(0.9$ to 1.6$)$ \\
\hline \multicolumn{5}{|c|}{ Self-reported duration of mouse use at work, $\mathrm{h} /$ day } \\
\hline 0 to $<2$ & 1 & 1 & 1 & 1 \\
\hline 2 to $<4$ & $0.9(0.6$ to 1.4$)$ & 1.110 & $1.0(0.7$ to 1.3$)$ & $1.1(0.8$ to 1.5$)$ \\
\hline$\geq 4$ & $1.5(1.0$ to 2.2$)$ & $1.4(0.9$ to 2.1$)$ & $1.6(1.2$ & $1.5(1.1$ \\
\hline \multicolumn{5}{|c|}{ Recorded duration of total computer use at work, h/week } \\
\hline 1 to $<10$ & 1 & 1 & 1 & 1 \\
\hline 10 to $<14$ & $1.0(0.7$ to 1.4$)$ & $1.0(0.7$ to 1.5$)$ & $1.0(0.7$ to 1.4$)$ & $1.2(0.8$ to 1.6$)$ \\
\hline 14 to 36 & $0.9(0.6$ to 1.4$)$ & $0.9(0.6$ to 1.4$)$ & $0.8(0.5$ to 1.1$)$ & $0.8(0.6$ to 1.1$)$ \\
\hline \multicolumn{5}{|c|}{ Recorded duration of mouse use at work, h/week } \\
\hline 0 to $<5$ & 1 & 1 & 1 & 1 \\
\hline 5 to $<7$ & $0.8(0.5$ to 1.2$)$ & $0.8(0.6$ to 1.2$)$ & $0.8(0.6$ to 1.1$)$ & $0.8(0.6$ to 1.1$)$ \\
\hline 7 to 22 & $0.9(0.6$ to 1.3$)$ & $0.9(0.6$ to 1.3$)$ & 0.8 (0.5 to 1.1$)$ & $0.8(0.6$ to 1.1$)$ \\
\hline \multicolumn{5}{|c|}{ Recorded duration of keyboard use at work, $\mathrm{h} /$ week } \\
\hline 0 to $<2$ & 1 & 1 & 1 & 1 \\
\hline 2 to 3 & $0.8(0.6$ to 1.2$)$ & $1.0(0.7$ to 1.4$)$ & $0.9(0.6$ to 1.2$)$ & $1.1(0.8$ to 1.6$)$ \\
\hline 3 to 13 & $0.7(0.5$ to 1.1$)$ & $0.7(0.5$ to 1.1$)$ & $0.8(0.5$ to 1.1$)$ & $1.0(0.7$ to 1.4$)$ \\
\hline
\end{tabular}

*Self-reported duration of total computer use at work (10310 observations) and selfreported duration of mouse use at work (10307 observations) were adjusted for factor no 1 (see appendix 1) until 6, 12, 13, 15, 27, 30,35. Recorded duration of total computer use at work (3958 observations) and recorded duration of keyboard use at work (3956 observations) were adjusted for no $2,5,6,8,9,12,13,15$, and recorded duration of mouse use at work (3956 observations): adjusted for no 2, 5, 6, 8, 9, 12, 13, 15 and 30.

†Self-reported duration of total computer use at work (10 959 observations) was adjusted for factor no 1 (see appendix 1) until 3,6, 14 until 16, 24, 27, 31 and 42. Self-reported duration of mouse use at work (10 987 observations) was adjusted for no 1, 2, 6, 14, 24, 27, 31, 42. Recorded duration of total computer use at work (3940 observations) was adjusted for no 1 until $3,6,10,13$ until $16,30,42$, recorded duration of mouse use at work (4134 observations) was adjusted for no $1,2,6,10,11,14,15,30,42$, and recorded duration of keyboard use at work (4125 observations) was adjusted for no 1, 2, 6, 10, 11 , 14 until 16, 30, 42.

$\mathrm{RR}$, rate ratio. 


\section{Association between recorded duration of computer use and severe symptoms}

Only two previous studies have investigated the relationship between the recorded duration of computer use at work and the onset of arm-wrist-hand and neck-shoulder symptoms. ${ }^{12} 13$ In contrast to our findings, both studies found a statistically significant, positive association between the recorded duration of computer use at work and the onset of arm-wrist-hand and neck-shoulder symptoms. This difference in findings between the current and previous studies might in part be explained by the time window between measurement of exposure and outcome. In the current study, it was 3 months, and in the previous studies it was 1 week and 1 day. ${ }^{12}{ }^{13}$ In addition, case definitions were different between studies. In the current study, subjects needed to report symptoms of sufficient intensity in the past 3 months, whereas in the previous studies, subjects had to report symptoms of sufficient intensity on 1 day. ${ }^{12}{ }^{13}$ However, Andersen and coworkers failed to find any association with prolonged symptoms, ${ }^{12}$ which compares to the findings in the current study, in which severe symptoms needed to be present regularly or prolonged during the last 3 months. Taken together, the results of the currently available studies suggest that the recorded duration of computer use at work is associated with a moderately increased risk of acute musculoskeletal symptoms. However, no association seems to be present with severe or prolonged symptoms.

\section{Discrepancy in findings between self-reported and recorded duration of computer use}

One of the explanations for the discrepancy in findings between self-reported and recorded duration of computer use may be selection bias. Because of the number of missing data, the number of available observations for the analyses with recorded computer duration was far lower than for the analyses with selfreported data. However, the identified associations between the self-reported duration of computer use at work and the onset of arm-wrist-hand and neck-shoulder symptoms were identical when selecting the subgroup of observations for which the recorded duration of computer use was available. In addition, the baseline characteristics for the participants with and without software-recorded computer duration did not differ.

A second explanation might be that differential misclassification of computer duration due to symptoms has led to spurious associations between the self-reported duration of computer use at work and the onset of arm-wrist-hand and neck-shoulder symptoms. Most studies investigating differential and non-differential misclassification of computer use have shown that misclassification is largely independent of symptom status, $^{721}$ although this was not always the case. ${ }^{8}$ It should also be noted that post hoc analysis of a subsample of the PROMO data showed no association between the degree of overestimation by self-report as compared with software recordings and the onset of upper-extremity symptoms, for severe or more mild symptoms (ie, regular or prolonged symptoms in the last 3 months regardless of level of pain intensity or use of pain medication). ${ }^{6}$ Therefore, we think that a potential differential misclassification in self-reported computer use due to mild discomfort is not likely to have influenced our results importantly.

A third explanation for the discrepancy in finding between selfreported and recorded duration of computer use at work might be that they do not measure the same construct. The correlation between self-reported and recorded data in this study was 0.2 at a maximum. In other studies, correlations between 0.36 and 0.61 have been reported. ${ }^{6} 8$ Therefore, it may be that self-reports measure a different construct than software recordings. Routinely collected data in occupational epidemiology, such as physical, psychosocial and individual factors, together with recorded computer-use data explained at a maximum 38\% of the variance in the self-reported duration of computer use at work. ${ }^{8}$ This limited explained variance could be related to limited precision of self-reports and/or unmeasured determinants of the self-reported duration of computer use at work.

\section{General limitations and strengths of the study}

The limitations of the study include the high number of missing values owing to technical problems, the relatively low participation rate and the fact that internal validity is threatened by (residual) confounding or effect modification. The cut-off point for missing data of $70 \%$ (ie, the number of recorded days was less than $70 \%$ of the expected workdays) was arbitrary; however, as mentioned before, selection bias did not seem to be present. Based on the fact that the between-subject variation was five times larger than the within-subject variation, we think that imputation of the data was legitimate. Moreover, univariate associations with the outcome variables were similar for original data and original data supplemented with imputed data. The low participation rate of the study is in line with the trend of declining participation rates in epidemiological studies. ${ }^{26}$ However, since no large differences between participants and non-participants were found in the present study, we do not expect different results if larger participation rates had been reached.

The strengths of this study include the long follow-up duration, measuring computer duration both with self-reports and with software recordings, and the external validity of the results. External validity is large, since we did not have strict inclusion criteria, and we included a wide array of jobs and functions. Although we had only a small proportion of office workers who used the computer for a short duration per day, and therefore limited exposure contrast, we think this situation is fairly representative of most modern office workers.

\section{Generalisability of the results}

In the present study, no association was found between software-recorded duration of computer use and the onset of severe arm-wrist-hand and neck-shoulder symptoms. Even though the results challenge the often-proposed causal relation between long duration of computer use and arm-wrist-hand symptoms or neck-shoulder symptoms, it may be too soon to abandon regulations limiting computer duration in order to prevent these symptoms

First of all, it should be borne in mind that these results only apply to the current case definition of severe symptoms that the participant experienced regularly or prolonged in the past 3 months. Given the fact that a moderate relation was found between software-recorded duration of computer use and acute arm-wrist-hand and neck-shoulder symptoms in previous studies, ${ }^{12}{ }^{13}$ it could be that other factors play a role in the onset of acute or mild symptoms as in the onset of severe symptoms or aggravation of the pain.

Second, this conclusion applies only to a time window of 3 months, and it is possible that a longer accumulation of computer duration is needed before severe symptoms arise. To date, the exposure-response latency in the onset of armwrist-hand symptoms or neck-shoulder symptoms is to a large extent unknown. 
Finally, in this study only the effect of the mean duration of computer use was studied. It is possible that other measures of exposure estimates play a role in the onset of severe armwrist-hand or neck-shoulder symptoms-for example, peak exposures for a short duration owing to reaching deadlines or variability in exposures across days or weeks. Therefore, we recommend that more refined exposure estimates of computer use at work be developed and studied in relation to the onset of symptoms and that the effect of a time window between exposure and musculoskeletal outcomes be explored further.

\section{CONCLUSION}

In the present study, no association was found between the recorded duration of computer use at work and the onset of severe arm-wrist-hand and neck-shoulder symptoms using an exposure window of 3 months. In contrast, a positive association was found between the self-reported duration of computer use at work and the onset of severe arm-wrist-hand and neck-shoulder symptoms. The different findings for selfreported and recorded duration of computer use could not be explained satisfactorily.

Competing interests None.

Patient consent Obtained.

Ethics approval Ethics approval was provided by the Medical Ethics Committee of the VU University Medical Centre.

Provenance and peer review Not commissioned; externally peer reviewed.

\section{REFERENCES}

1. Hadler NM. A keyboard for 'Daubert.' J Occup Environ Med 1996;38:469-76.

2. Silverstein MA, Silverstein BA, Franklin GM. Evidence for work-related musculoskeletal disorders: a scientific counterargument. J Occup Environ Med 1996;38:477-84.

3. Nathan PA, Meadows KD. Neuromusculoskeletal conditions of the upper extremity: are they due to repetitive occupational trauma? Occup Med 2000;15:677-93.

4. Punnett L, Wegman DH. Work-related musculoskeletal disorders: the epidemiologic evidence and the debate. J Electromyogr Kinesiol 2004;14:13-23.

5. IJmker S, Huysmans MA, Blatter BM, et al. Should office workers spend fewer hours at their computer? A systematic review of the literature. Occup Environ Med 2007:64:211-22.

6. IJmker S, Leijssen JNM, Blatter BM, et al. Test-retest reliability and validity of self-reported duration of computer use at work. Scand J Work Environ Health 2008:34:113-19.

7. Heinrich J, Blatter BM, Bongers PM. A comparison of methods for the assessment of postural load and duration of computer use. Occup Environ Med 2004;61:1027-31.

8. Mikkelsen S, Vilstrup I, Lassen CF, et al. Validity of questionnaire self-reports on computer, mouse and keyboard usage during a four-week period. Occup Environ Med 2007;64:541-7

9. Armstrong BG. Effect of measurement error on epidemiological studies of environmental and occupational exposures. Occup Environ Med 1998;55:651-6.

10. Blangsted AK, Hansen K, Jensen C. Validation of a commercial software package for quantification of computer use. Int J Ind Ergon 2004;34:237-41.

11. Douwes $\mathbf{M}$, de Kraker $\mathrm{H}$, Blatter BM. Validity of two methods to assess computer use: self-report by questionnaire and computer use software. Int $J$ Ind Ergon 2007; 37:425-31.

12. Andersen $\mathbf{J H}$, Harhoff $\mathrm{M}$, Grimstrup $\mathrm{S}$, et al. Computer mouse use predicts acute pain but not prolonged or chronic pain in the neck and shoulder. Occup Environ Med 2008;65:126-31.

13. Chang $\mathbf{C H}$, Amick BC 3rd, Menendez CC, et al. Daily computer usage correlated with undergraduate students' musculoskeletal symptoms. Am J Ind Med 2007:50:481-8.

14. IJmker S, Blatter BM, van der Beek AJ, et al. Prospective research on musculoskeletal disorders in office workers (PROMO): study protocol. BMC Musculoskelet Disord 2006; 7:55.

15. Waersted M, Bjorklund RA, Westgaard RH. Shoulder muscle tension induced by two VDU-based tasks of different complexity. Ergonomics 1991;34:137-50.

16. Visser B, De Looze M, De Graaff $M$, et al. Effects of precision demands and mental pressure on muscle activation and hand forces in computer mouse tasks. Ergonomics 2004:47:202-17.

17. Karlqvist LK, Bernmark E, Ekenvall $L$, et al. Computer mouse position as a determinant of posture, muscular load and perceived exertion. Scand J Work Environ Health 1998;24:62-73.
18. Aarås A, Fostervold $\mathrm{KI}$, Ro 0 , et al. Postural load during VDU work: a comparison between various work postures. Ergonomics 1997;40:1255-68.

19. Hildebrandt VH, Bongers PM, van Dijk FJ, et al. Dutch musculoskeletal questionnaire: description and basic qualities. Ergonomics 2001;44:1038-55.

20. Kuorinka I, Jonsson B, Kilbom K, et al. Standardised Nordic questionnaires for the analysis of musculoskeletal symptoms. Appl Ergonomics 1987:18:233-37.

21. Punnett L, Bergqvist U. Visual Display Unit Work and Upper Extremity Musculoskeletal Disorders: a Review of Epidemiological Findings. Solna (Sweden): Arbeitslivinstitute, 1997

22. Von Korff M, Ormel J, Keefe FJ, et al. Grading the severity of chronic pain. Pain 1992; 50:133-49.

23. Marcus $\mathbf{M}$, Gerr $\mathrm{F}$, Monteilh $\mathrm{C}$, et al. A prospective study of computer users: II. Postural risk factors for musculoskeletal symptoms and disorders. Am J Ind Med 2002; $\mathbf{4 1 : 2 3 6 - 4 9}$

24. Zou GA. Modified Poisson regression approach to prospective studies with binary data. Am J Epidemiol 2004;159:702-6.

25. Kleinbaum DG, Kupper LL, Muller KE, et al. Chapter 11 Confounding and interaction in regression. In: Kleinbaum DG, Kupper LL, Muller KE, et al. Applied Regression Analysis and Other Multivariable Methods. 3rd Edn. Pacific Grove, CA: Brooks/Cole Publishing Company, 1998:p.186-211.

26. Galea S, Tracy M. Participation rates in epidemiological studies. Ann Epidemiol 2007:17:643-53.

\section{APPENDIX 1}

\section{Overview of potential confounders and potential effect modifiers}

\begin{tabular}{l}
\hline Potential confounders \\
\hline Personal factors \\
1. Gender* \\
2. Age* \\
3. Education level* \\
4. Body mass index \\
5. Symptoms in the arm-wrist-hand \\
region in the past year causing \\
disability or medical consumption* \\
6. Symptoms in the in the \\
neck-shoulder region past year \\
causing disability or medical \\
consumption*
\end{tabular}

7. No of years of daily computer use at work $^{*}$

8. Managerial job

9. Mouse handedness

Psychosocial factors

10. Cognitive demands $\dagger \quad$ 10. Cognitive demands

11. Effort‡

11. Effort

12. Reward $\S$

13. Overcommitment

14. Decision authority**

15. Task variation††

Workposture and workstyle factors

16. Arm support during keyboard use

17. Arm support during mouse use

18. Touch typing skill

19. Monitor height

20. Mouse location

21. Lack of space on desk for proper mouse use

22. Mouse functioning

23. Use of break and reminder software

24. Work continuation during formal breaks*

25. Distance table edge to keyboard $<10 \mathrm{~cm}$

Physical activity at work

26 . Increase in duration of computer use in the past year

27. Using computer and telephone at the same time at work

28. General discomfort while working at desk
16. Arm support during keyboard use 17. Arm support during mouse use 18. Touch typing skill 19. Monitor height 20. Mouse location

21. Lack of space on desk for proper mouse use

22. Mouse functioning

23. Use of break and reminder software 24. Work continuation during formal breaks*

27. Using computer and telephone at the same time at work 
Appendix 1 Continued

\begin{tabular}{ll}
\hline Potential confounders & Potential effect modifiers \\
\hline 29. Precision demands during mouse & 29. Precision demands during mouse use \\
use & \\
30. Squeezing with hands at work & \\
31. Repetitive tasks at work excluding & \\
computer use* & \\
32. Working with hands above & \\
shoulder height* & \\
33. Pushing or pulling* & \\
34. Manual materials handling* & \\
Physical activity in leisure time & \\
35. Duration of computer use during & 35. Duration of computer use \\
leisure time & during leisure time \\
36. Moderate intensity physical activity & \\
37. High intensity physical activity & \\
38. Strength training of upper body &
\end{tabular}

Appendix 1 Continued

Potential confounders $\quad$ Potential effect modifiers

39. Playing golf

40. Playing sports involving upper extremities (eg, racket sports,

volleyball)

41. Hand intensive activities during

leisure time

Other

42. Work disability due to neck-shoulder or arm-wrist-hand

symptoms among acquaintances

* Only in baseline questionnaire and treated as a constant in 2-year follow-up.

†Cronbachs alpha $=0.73$ (baseline); 0.76 (after one year of follow-up).

$\neq$ Cronbachs alpha $=0.69$ (baseline); 0.59 (after one year of follow-up).

$\S$ Cronbachs alpha $=0.81$ (baseline): 0.62 (after one year of follow-up).

ๆCronbachs alpha $=0.74$ (baseline); 0.78 (after one year of follow-up).

${ }^{* *}$ Cronbach alpha $=0.74$ (baseline); 0.71 (after 1-year follow-up).

$\dagger \dagger$ Cronbachs alpha $=0.84$ (baseline); 0.84 (after one year of follow-up) 